\title{
Empowering Key Populations (Kps) to Effectively Demand for Equal HIV/AIDS Services
}

\author{
Susan $\mathrm{A}^{{ }^{*}}$, Patrick $\mathrm{O}^{1}$, Dennis $\mathrm{O}^{1}$ and Joseph $\mathrm{B}^{2}$ \\ ${ }^{1}$ Action Group for Health human rights and HIV/AIDS, (AGHA), Uganda \\ ${ }^{2}$ THETA, Uganda
}

*Corresponding author: Susan A, Action Group for Health human rights and HIV/AIDS, (AGHA), Kampala, Uganda, 24667, Tel: +25641348491, E-mail: info@agha.or.ug, atuhuras@gmail.com

Citation: Susan A, Patrick O, Dennis O, Joseph B (2017) Empowering Key Populations (Kps) to Effectively Demand for Equal HIV/AIDS Services. J AIDS HIV Infec 3(2): 201. doi: 10.15744/2454-499X.3.201

Received Date: October 10, 2016 Accepted Date: October 10, 2016 Published Date: December 05, 2017

\begin{abstract}
Background: AGHA in partnership with THETA and MNL with funding from CDC is implementing a Local Capacity Initiative project aimed at building capacity of CSOs working with KPs in Mukono, Kampala and Wakiso to advocate for improved HIV services. In Uganda, HIV prevalence among the general population stands at an average of $7.3 \%$ while among SWs is $35-37 \%$ and MSM at $13.7 \%$ between the age of $18-24$.Over $40-50 \%$ of the new infections come from KPs (UAC, HIV /AIDS Indicator survey 2011). Programs targeting KPs continue to be characterized by limited coverage, poorly linked care, treatment and referral services. The project has increased capacity of 15 CSOs to demand accountability from government on national commitments on KPs; increased capacity of KPs to identify the legal and policy framework that impede equitable access, increased participation and representation of community leaders and KPs living with HIV in the governance structures that influence health services delivery.

Description: The project equipped KPs with skills to generate issues on the delivery of HIV/AIDS services using social accountability approaches like the community scorecard in six government health facilities. The scorecard assessed the extent to which government has met its commitment towards achieving zero new infections, discrimination and HIV/AIDS related deaths within the national HIV/ AIDS response. The findings showed high stigma and discrimination of KPs by health workers, no peer led services, no commodities like lubricants and condoms, criminative laws and policies.

Lessons learned: 10 peers from each KPs category have been trained on ART adherence, home based care, HTC, health rights and advocacy. 3 Joint district planning meetings have been conducted in which issues affecting HIV service delivery for KPs have been prioritized.Capacities of 50 health workers have been built on dealing with stigma and discrimination.

Conclusions/Next steps: Uganda's response has had challenges in the recent past due to limited priority in Prevention, treatment and programming for KPs and yet research shows KPs are the leading avenue for new infections. As a consortium, we continue to contribute to influence the national response through advocacy and community dialogue with duty bearers to enable KPs access HIV services and empower them in voicing out their demands.
\end{abstract}

Keywords: Key Populations; Men who have sex with men; Community scorecards

List of abbreviations: SW: Sex Workers; MSM: Men who have Sex with Men: UAC: Uganda AIDS Commission: KPs: Key Populations: $\mathrm{H} / \mathrm{C}:$ Health Center

\section{Introduction}

In Uganda, the HIV epidemic continues to be generalized with the prevalence standing at an average of $7.3 \%$ in the general population while among Sex Workers at 35-37\% and MSM at 13.7\% between the age of 18-24 [1]. The burden of HIV in Uganda represented by the number of persons in the country living with HIV has increased in the last five years from 1.2 million to 1.6 million [2]. It is further reported that there is limited comprehensive programming and inadequate coverage of HIV prevention and care services in the Ugandan health care settings for key populations. Men who have sex with men, sex workers and transgender persons still face a lot of stigma and discrimination and have limited social protection space in communities including health facilities. These factors hinder their access to services and exclude them from meaningful participation in the HIV response. Local key populations led CSOs in Uganda have been instrumental in reaching out to these communities both in service provision and advocacy for improved access to HIV services. However, their work remains constrained by their limited capacity in advocacy and resources as well as the difficult legal and policy environment in which they operate. 
The 1993 World Development Report, investing in Health, considered strengthening accountability as one of the core elements of health sector reform. This ignited a trend to incorporate participation and accountability as part of the planning process for health sectors, and has been reinforced by various players in civil society, bilateral and multilateral donors, and governments towards a vision of a more effective, efficient and equitable access to health care [3]. In September-October 2012, the Uganda Network of AIDS Services Organizations (UNASO), commissioned a Uganda AIDS scorecard which revealed a number of issues that affect enforcement of governance and accountability in the HIV\&AIDS response. However, over the years the HIV response has registered improvement in citizen participation in review of the response performance mainly in the general population.

In the same manner the local Capacity Initiative (LCI) project adopted the community scorecard to enable key populations generate issues on the delivery of HIV/AIDS services in six government health facilities namely: Kawaala H/C IV, Kiira Health H/C III, Kisenyi H/C IV, Kojja H/C IV, Mukono H/C IV and Kajjansi H/C IV. The scorecard assessed the extent, to which government has met its commitment towards achieving the 90, 90, 90 target within the national HIV/AIDS response. The assessment was based on standard indicators set by the Ministry of Health and community identified indicators in the provision of the basic minimum health care package to key populations with a particular focus on MSMs, sex workers and transgender persons.

\section{Objective of the scorecard}

The main objective of the score card was to identify HIV and AIDS service delivery gaps for key populations in the 3 targeted districts of Mukono, Wakiso and Kampala.

\section{Specific objectives}

i. To assess the opinion and perceptions of the key populations and health workers on the performance of health units in delivering quality HIV and AIDS services.

ii. To provide a platform for the key populations community to engage with service providers.

iii. To generate key recommendations to address HIV and AIDS service delivery gaps affecting key populations.

\section{Materials and Methods}

Qualitative research approaches using score card was applied. Key populations were randomly selected prior to the score card meetings and were engaged on how to facilitate the discussions while assessing the different indicators related to delivery of HIV/AIDS services. A non-numeric scale was adopted for scoring against performance criteria to accommodate key populations community members with no or low literacy levels to participate during the meeting. Colors were used for three levels of rating: Red, implying that performance criteria rated with that color was bad and needed attention. The numeric equivalent assigned to red was mark 1 on a scale of 3.Yellow was for performance indicators rated as satisfactory, attracting marks 2 out of 3, implying that the performance criteria would receive second priority after those rated bad. Green was for performance criteria rated good, attracting marks 3 implying good performance. The rationale for this scoring was that over time performance criteria with red/ yellow coloring should be monitored over time to ensure improvement through adoption of various advocacy strategies. In order to draw a better understanding of the scores, the reasons for the low and high scores were documented for engagement during the interface dialogue session. To get an average score of the indicator for a district, the different scores from different health facilities were summed up and divided by three.

\section{Sample Size}

A total of 97 people took part in the scorecard process. Sixty (60) were health workers with 10 from each health facility, 33 key populations (sex workers, MSMs and transgender persons) and 4 district representatives all selected from the three districts of Mukono, Kampala and Wakiso. The number of key population was low due to the fear of disclosing their identity given Uganda's legal framework that criminalizes same sex and sex work.

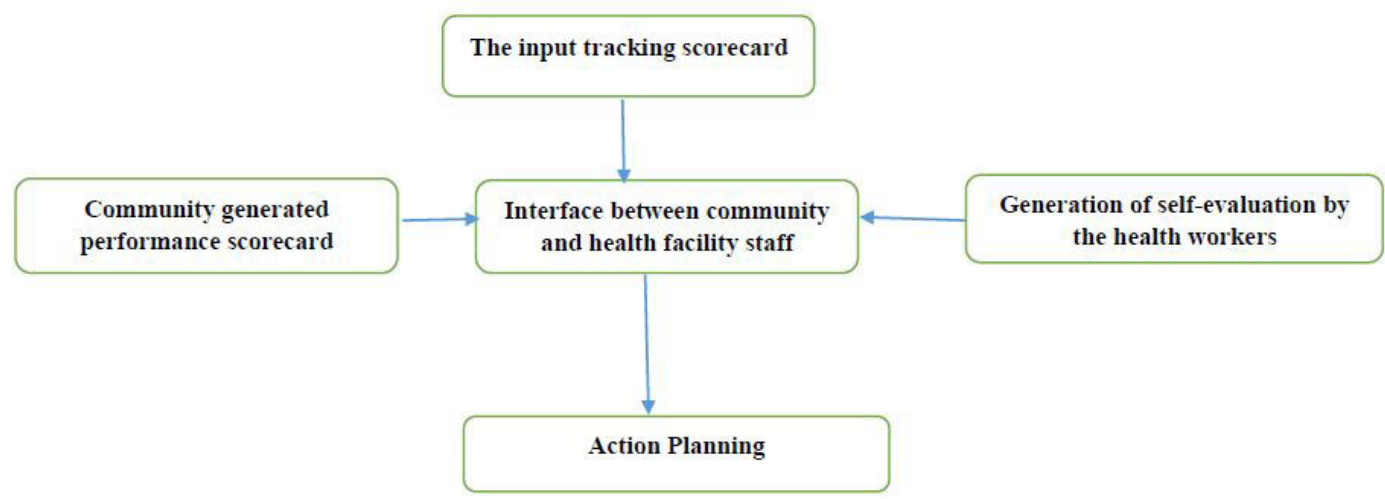

Figure 1: The scorecard process 
i. The input tracking scorecard: This was largely comprised of the health supply side data looking at the minimum health care package as provided by ministry of health in the national health policy framework. Inventories of inputs like drugs, equipment and other commodities like lubricants, condoms etc. formed the part of indicators for assessment and tracking.

ii. Community generated performance scorecard: The participants were classified into two focus groups of service providers (health workers) and service users (Key Populations), having decided on the performance criteria. The facilitators asked the key populations focus groups to generate relative scores for each of the indicator.

iii. Generation of self-evaluation by the health workers: In order to get the perception of the service providers and understand the thematic challenges affecting the working environment of health workers, just like the key populations focus group the health workers also scored themselves against the same indicators. The reasons for the scores helped to come up with suggestions for improving the state of health service at the respective facilities.

iv. Interface between community and health facility staff: Each group was allowed to choose among their respective participants to present their assessment scores that formed part of the discussion points during the interface meeting. This final stage in the community score card process held the key to ensuring that the feedback of the community is taken into account and that concrete measures are taken to remove the shortcomings of health service delivery. A conscious approach was taken to sensitize both the Key Populations community and health service providers about the feelings and constraints of each side to ensure that the dialogue does not become adversarial and that a relationship of mutual understanding is built between the client and the service providers.

v. Action Planning: A common point of agreement during the community scorecard process was the development of a joint health challenges alleviation strategy both from the supply side and demand side. The action plan formed the basis of follow ups and local government planning and budgeting for health services. To further strengthen the demand side AGHA developed the capacity of the MARPs to monitor and make follow up on the action plan.

\section{Results}

The findings were extracted using six domains which included HIV Prevention Services, HIV Testing and Counseling (HTC), Treatment, Care and Prevention, Management of Co-infections and Co-Morbidities, Sexual and Reproductive Health, Functionality of the Laboratory, and Other Health Systems each with a set of indicators. However, a lot of advocacy was concentrated on those domains that scored poorly during the assessment.

\section{HIV Prevention Services}

In regard to HIV prevention services, the domain had five indicators which included availability of condoms both male and females, availability of lubricant, Availability of post exposure prophylaxis, Availability of Voluntary medical male circumcision (VMMC) and BCC/IEC Messages that increase uptake of HIV prevention interventions (peer model, materials-provider materials).However, under this domain availability of condoms, lubricants and BCC/IEC Messages that communicate increase in uptake of HIV prevention interventions specific to MARPs were not available

\section{Availability of condoms}

It was noted that all health facilities had male condoms but were not enough for the available demand. The demand for female condoms was very low with limited awareness beyond the facilities. The indicator scored satisfactory implying that there was need for increased advocacy to ensure increased supply and awareness.

\section{Availability of lubricants}

Within the national basic kit for essential health supplies and medicines for health facilities assessed, lubricants were not considered in the kit yet very vital for key populations. During scorecard process availability of lubricants in health facilities scored poor with only one health facility (Kisenyi health center) out six that was supplied with only 10 pieces of KY jelly in a quarter. It should be noted that the quantity supplied was very low given the number of users that access services from the health center. It was also observed that the health facility did not endeavor to create awareness to the key populations community of the few pieces of lubricants received which in the end expired from the stores.

\section{Availability of BCC/IEC Messages that communicate increase in uptake of HIV prevention interventions for MARPs}

Although some health facilities had BCC/IEC materials that communicate increase in uptake of HIV prevention interventions none of them were specific to key populations.

\begin{tabular}{|c|c|c|c|c|c|c|c|}
\hline Indicators & \multicolumn{7}{|c|}{ Health Units Scores } \\
\hline HIV Prevention services & \multicolumn{2}{|c|}{ Mukono } & \multicolumn{2}{|c|}{ Wakiso } & \multicolumn{2}{|c|}{ Kampala } & Overall Score \\
\hline & $\begin{array}{l}\text { Kojja } \\
\text { Health } \\
\text { Center }\end{array}$ & $\begin{array}{c}\text { Mukono } \\
\text { Health } \\
\text { Center }\end{array}$ & $\begin{array}{c}\text { Kajjansi } \\
\text { Health } \\
\text { Center }\end{array}$ & $\begin{array}{l}\text { Kiira } \\
\text { Health } \\
\text { Center }\end{array}$ & $\begin{array}{l}\text { Kisenyi } \\
\text { Health } \\
\text { Center }\end{array}$ & $\begin{array}{l}\text { Kawala } \\
\text { Health } \\
\text { Center }\end{array}$ & \\
\hline
\end{tabular}




\begin{tabular}{|c|c|c|c|c|c|c|c|}
\hline Indicators & \multicolumn{7}{|c|}{ Health Units Scores } \\
\hline HIV Prevention services & \multicolumn{2}{|c|}{ Mukono } & \multicolumn{2}{|c|}{ Wakiso } & \multicolumn{2}{|c|}{ Kampala } & Overall Score \\
\hline Availability of condoms & \multirow{3}{*}{ Satisfactory } & \multirow{3}{*}{ Satisfactory } & \multirow{3}{*}{ Satisfactory } & \multirow{3}{*}{ Satisfactory } & \multirow{3}{*}{ Satisfactory } & \multirow{3}{*}{ Satisfactory } & \multirow{3}{*}{ Satisfactory } \\
\hline Male & & & & & & & \\
\hline Females & & & & & & & \\
\hline Availability of lubricants & Poor & Poor & Poor & Poor & Poor & Poor & Poor \\
\hline $\begin{array}{l}\text { BCC/IEC Messages that increase uptake } \\
\text { of HIV prevention interventions (peer } \\
\text { model, materials-provider materials) }\end{array}$ & Satisfactory & Satisfactory & Satisfactory & Satisfactory & Satisfactory & Satisfactory & Satisfactory \\
\hline
\end{tabular}

Table 1: Assessment scores for HIV Prevention services

\section{Other Health systems}

Other health systems had nine indicators of which 5 scored poor with rest scoring satisfactory and none was good.

i. Attitude of health workers towards key populations: The attitude of health workers towards the key populations was rated as poor across all the assessed health facilities most especially towards men who have sex with men and transgender persons. The poor attitude was fueled by a conservative Christian and cultural beliefs that consider key populations immoral and societal misfits.

ii. Health Management Information System (HMIS) timelines and quality reporting on key populations services: The HMIS designed in1985 to initially capture and analyze morbidity data for selected communicable and non-communicable diseases, immunization and family planning services was revised seven years ago to capture vital health information. The core function of Uganda's HMIS currently is to establish and maintain a comprehensive source of health and management information for planning, monitoring and evaluation of the health sector strategic plan. Although government supplied all health facilities with HMIS reporting tools none of the tools captures data related to key populations.

iii. Social mobilization by VHTs: In 2002, Uganda began implementing a national community health worker program called the village health teams (VHTs) considered as the first level of health care in Uganda.VHTs are charged with a responsibility of empowering communities to take in the decisions that affect their health, mobilize communities for health programs and strengthen the delivery of health services through referral and linkage at household level. However, there has not been a deliberate effort to use these structures to reach out to key populations. Even in terms of key populations' representation in these structures was found to be none existent in all the assessed health facilities. The reason for this was that the VHTs would make the situations harder because stigma was even higher among them as compared to health workers.

iv. Knowledge of hotspots or mapped areas for MARPs: No hot spot for MSMs was reported to be known in Mukono and Wakiso districts, however two were reported by Kawaala health center in Kampala.

v. Trained peers on referral and follow-ups: No health facility had peer educators from all key populations categories.

\begin{tabular}{|c|c|c|c|c|c|c|c|}
\hline \multirow{3}{*}{$\begin{array}{c}\text { INDICATORS } \\
\text { Other Health Systems }\end{array}$} & \multicolumn{7}{|c|}{ HEALTH UNITS SCORES } \\
\hline & \multicolumn{2}{|c|}{ Mukono } & \multicolumn{2}{|c|}{ Wakiso } & \multicolumn{2}{|c|}{ Kampala } & \multirow[t]{2}{*}{ Overall Score } \\
\hline & $\begin{array}{l}\text { Kojja } \\
\text { Health } \\
\text { Center }\end{array}$ & $\begin{array}{l}\text { Mukono } \\
\text { Health } \\
\text { Center }\end{array}$ & $\begin{array}{l}\text { Kajjansi } \\
\text { Health } \\
\text { Center }\end{array}$ & $\begin{array}{l}\text { Kiira } \\
\text { Health } \\
\text { Center }\end{array}$ & $\begin{array}{l}\text { Kisenyi } \\
\text { Health } \\
\text { Center }\end{array}$ & $\begin{array}{l}\text { Kawala } \\
\text { Health } \\
\text { Center }\end{array}$ & \\
\hline $\begin{array}{l}\text { Attitude of health workers towards key } \\
\text { populations }\end{array}$ & Poor & Poor & Poor & Poor & Poor & Poor & Poor \\
\hline $\begin{array}{l}\text { Trained health workers on gender } \\
\text { sensitivity }\end{array}$ & Satisfactory & Satisfactory & Satisfactory & Satisfactory & Satisfactory & Satisfactory & Satisfactory \\
\hline $\begin{array}{l}\text { Level of awareness of health workers } \\
\text { about key populations }\end{array}$ & Satisfactory & Satisfactory & Satisfactory & Satisfactory & Satisfactory & Satisfactory & Satisfactory \\
\hline HMIS reporting mechanisms & Satisfactory & Satisfactory & Satisfactory & Satisfactory & Satisfactory & Satisfactory & Satisfactory \\
\hline $\begin{array}{l}\text { HMIS timelines and quality reporting on } \\
\text { MARPS services }\end{array}$ & Poor & Poor & Poor & Poor & Poor & Poor & Poor \\
\hline Social mobilization by VHTs & Poor & Poor & Poor & Poor & Poor & Poor & Poor \\
\hline Community outreaches & Satisfactory & Satisfactory & Satisfactory & Satisfactory & Satisfactory & Satisfactory & Satisfactory \\
\hline Knowledge of hotspots/mapped areas & Poor & Poor & Poor & Poor & Poor & Poor & Poor \\
\hline Trained peers on referral and follow-ups & Poor & Poor & Poor & Poor & Poor & Poor & Poor \\
\hline
\end{tabular}

Table 2: Assessment scores for other health systems 


\begin{tabular}{|c|c|}
\hline GAPS Identified & Scorecard Outcomes \\
\hline Absence of lubricants & $\begin{array}{l}\text { Government through ministry of health procured lubricants in financial } \\
\text { year starting July 2016/2017 but has never distributed them to the respective } \\
\text { health facilities. }\end{array}$ \\
\hline $\begin{array}{l}\text { BCC/IEC Messages that increase uptake } \\
\text { of HIV prevention interventions (peer } \\
\text { model, materials-provider materials) }\end{array}$ & $\begin{array}{l}\text { BCC/IEC materials communicating increase in uptake of HIV prevention } \\
\text { services specific to key populations were produced and disseminated to all } \\
\text { health facilities. }\end{array}$ \\
\hline $\begin{array}{l}\text { Attitude of health workers toward key } \\
\text { populations }\end{array}$ & $\begin{array}{l}\text { Over } 100 \text { health workers were trained on gender and sexual diversity which } \\
\text { reduced stigma and discrimination hence resulting into more key popula- } \\
\text { tions accessing HIV services in the health facilities. }\end{array}$ \\
\hline Knowledge of hotspots/mapped areas & $\begin{array}{l}\text { Mapping of hotspots for sex workers was conducted by Uganda AIDS Com- } \\
\text { mission which led to an increase in out reaches targeting key populations. }\end{array}$ \\
\hline Trained peers on referral and follow-ups & $\begin{array}{l}10 \text { peers from each Key Populations category were identified and trained on } \\
\text { ART adherence, home based care, HTC, referral, health rights and advocacy. }\end{array}$ \\
\hline
\end{tabular}

\section{Recommendations}

- Ministry of Health should review the HMIS tool to capture specific data targeting key populations.

- The government should increase the health budget for national HIV response with a specific focus on key populations.

- Ministry of health should scale up trainings for health workers on care and treatment for key populations.

- Ministry of health and district health departments to intensify sensitization programs on health rights for key populations to reduce stigma.

\section{Conclusion}

For Uganda to realize her 90, 90, 90 target, it's important that all health workers adopt a non- stigmatizing and discriminative health service delivery approach which recognizes zero tolerance for exclusion.

\section{References}

1. UAC, HIV /AIDS Indicator survey (2011)

2. UAC, Uganda HIV and AIDS country progress report (2014)

3. World Bank (1993) World Development Report: Investing in Health. New York: Oxford University Press. (C) World Bank.

4. Ministry of health (MOH), HIV incidence projections 2013

5. UAC/UNAIDS HIV Modes of transmission and prevention response analysis,(2009)

6. Citizen Voice and Action: World Vision's Approach to Social Accountability. Jeff Hall, CORE Fall meeting, October 16, 2013

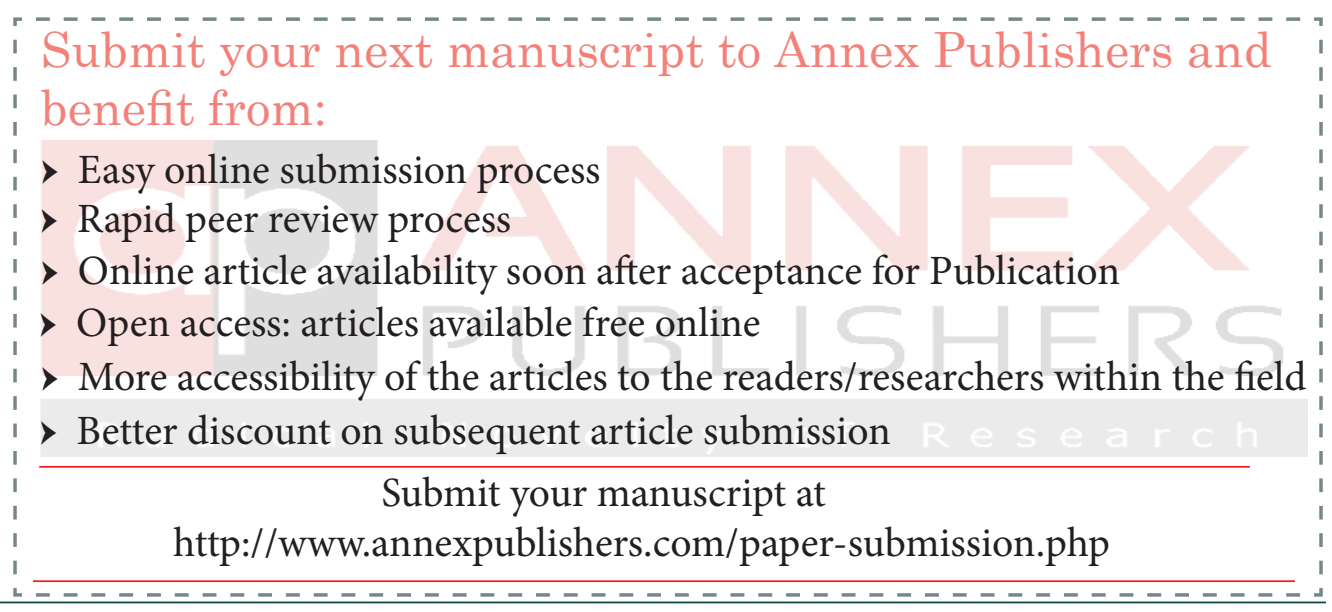

